\title{
Regulation of Cellular Metabolism During Synthesis and Expression of the Luminous System in Beneckea and Photobacterium
}

\author{
By DAVID M. KARL ${ }^{1}$ AND KENNETH H. NEALSON ${ }^{2 *}$ \\ 1 Department of Oceanography, University of Hawaii, Honolulu, Hawaii 96822, U.S.A. \\ 2 Marine Biology Research Division, Scripps Institution of Oceanography, \\ La Jolla, California 92093, U.S.A.
}

(Received 23 April 1979)

\begin{abstract}
Parameters of cellular energetics (ATP pools, adenylate energy charge, GTP pools and oxygen consumption) as well as bioluminescence and growth have been examined in batch cultures of four different species of luminous bacteria. The findings indicate that all of these energetic parameters remain constant throughout the growth cycle while bioluminescence is induced and increases many fold. These observations hold true for very bright strains during their dim and bright phases of growth, as well as for a luminescence-conditional strain under bright or dark conditions. The percentage of the total oxygen consumption that was due to bioluminescence was shown to vary by as much as a factor of $10^{3}$ during growth. For very bright cells, the oxygen consumption experiments suggest both that the energetic requirements of the bioluminescent system are significant, and that the quantum efficiency $\left(Q_{\mathrm{O}_{2}}\right)$ of the luciferase in vivo is quite high, possibly approaching $1 \cdot 0$. Similar considerations based on ATP pool size and energetic estimates of luminescence indicate that the luminous system in bright cells represents a small but possibly significant energy drain. Finally, two methodological features are discussed. First, it was shown that extracts of cells that have been grown in media devoid of inorganic phosphate contain a heat-stable ATPase activity, which can lead to falsely low ATP values. Second, it was shown that the interfering effect of GTP on the assay of ATP could be completely overcome by the addition of GDP to the assay mixture.
\end{abstract}

\section{INTRODUCTION}

Luminous bacteria have long intrigued microbial physiologists, partly because of the question of the energetics of bioluminescence: how much of the cellular energy goes into the production of light? What is the distribution of energy between anabolic pathways and bioluminescence during times of intense light emission, and what mechanisms control this distribution? The blue-green bacterial light is an unusual enzymic product, requiring about $50 \mathrm{kcal}(200 \mathrm{~kJ})$ per mol light. The reaction, catalysed by bacterial luciferase, requires both reduced flavin mononucleotide $\left(\mathrm{FMNH}_{2}\right)$ and a long-chain aldehyde as substrates. Both substrates are oxidized during light emission, and two molecules of reduced pyridine nucleotides (NADH) are presumably needed for each pair of molecules of substrate regenerated (Hastings \& Nealson, 1977). The luminous system can thus be viewed as a shunt (at the level of FMN) of the normal electron transport system, probably lowering the $\mathrm{P} / 2 \mathrm{e}$ ratio to one or less for the diverted electron flow.

Light-emitting capacity can vary greatly (from less than 1 to more than $10^{5}$ photons s$^{-1}$ cell ${ }^{-1}$ ) depending on the bacterial strain and its extent of induction (Hastings \& Nealson, 1977). For very bright cells a commitment of approximately $2 \times 10^{5}$ molecules NADH s ${ }^{-1}$ may thus be required to maintain the activity of the luminous system, and although ATP is 
not directly consumed in the light-emitting reaction, very bright cells might forego the synthesis of as much as $4 \times 10^{5}$ or $6 \times 10^{5}$ molecules ATP $\mathrm{s}^{-1}$ cell ${ }^{-1}$ by shunting electrons to oxygen via luciferase.

ATP measurements by Ulitzur \& Hastings (1978) and in our laboratory indicate that the intracellular ATP concentrations in luminous bacteria are between $0.2 \times 10^{-18}$ and $2 \cdot 0 \times$ $10^{-18} \mathrm{~mol}^{-1} \mathrm{ll}^{-1}\left(1 \cdot 2 \times 10^{5}\right.$ to $12 \times 10^{5}$ molecules ATP cell $\left.{ }^{-1}\right)$. Even if the ATP pool turns over one to several times per second (Harrison \& Maitra, 1969; Miovic \& Gibson, 1973; Chapman \& Atkinson, 1977), the effect of the activity of the bioluminescent system on the supply of ATP might be substantial in very bright cells. This drain is even more important if the quantum efficiency of luminescence in vivo is only $10 \%$, as has been reported for luciferase in vitro (Hastings, 1975).

Experiments conducted in the early 1900s by Harvey and others concluded that the luminous system in bright bacteria represented a major drain on cellular metabolism. These experiments involved measuring oxygen consumption due to bioluminescence as compared to that used for growth and respiration. Subsequent work in several laboratories has supported this view and led to the conclusion that in very bright bacteria the luminous system may account for 12 to $20 \%$ of the total oxygen consumed (see Harvey, 1952, for a discussion). As has recently been pointed out by several authors, the synthesis of the components of the light-emitting system may represent a significant energetic requirement of luminous bacteria. Luciferase is an inducible enzyme and in only a few bacterial generations can increase from negligible amounts to $5 \%$ or more of the soluble cellular protein (Hastings et al., 1965; Henry \& Michelson, 1970). During this induction, several soluble (Michaliszyn \& Meighen, 1976) and membrane-bound (Ne'eman et al., 1977) proteins of unknown, but presumably associated, function are co-induced.

Considerations such as these led Ulitzur \& Hastings (1978) to investigate fluctuations in ATP pools of Beneckea harveyi during growth in batch cultures. They found that simultaneously with the induction of the luminous system there was a marked (10-fold or more) decrease in the cellular ATP pool. They used a variety of mutants to determine which feature, if any, of the luminous system was responsible for the decrease in the ATP pool. However, they concluded that the enigmatic dip in cellular ATP was due neither to light emission nor to the synthesis of the luminous system. They proposed several possible explanations for their results, none of which they considered completely adequate. Adenylate energy charge was not studied, but during the dip in the ATP pool no substantial change in growth rate was noted, suggesting that cellular energy charge might be maintained.

Similar and more detailed investigations conducted using the non-luminous marine bacterium Beneckea natriegens (Niven et al., 1977) showed no fluctuations in either ATP pools or adenylate energy charge during growth in batch culture. However, there were many differences in both methods and growth media between these two reports, so the apparent discrepancy cannot be attributed solely to the fact that $B$. natriegens is a non-luminous species.

Because of these reported discrepancies, we have examined several parameters of cellular energetics (oxygen consumption, ATP pools, GTP pools and adenylate energy charge) for four species of marine luminous bacteria. The results presented in this paper indicate that the dip in the ATP pool is apparently due to the presence of a membrane-bound, heat-stable phosphatase (ATPase) activity which hydrolyses the ATP in the extracts. No ATP dip is observed when inorganic phosphate is included in the growth medium, and no (or very low) phosphatase activity can be demonstrated in the extracts. The intracellular levels of GTP are high during exponential growth. These levels of GTP can significantly affect the measurement of ATP made by standard methods using crude firefly luciferase, but the interference can be overcome by the addition of GDP. 


\section{METHODS}

Bacterial strains. Several species and strains of luminous bacteria were used in this study. Strain designations prefixed with B are those included in the study of Reichelt \& Baumann (1973); all other strains were described by Nealson \& Hastings (1977), using the methods of Reichelt \& Baumann (1973). The strains included: MJ-1, a bright strain of Photobacterium fischeri; B-61, an inducer-negative mutant strain of Photobacterium fischeri; B-392 (strain MAV), a well-characterized strain of Beneckea harveyi; B-404 (PP-404), a bright strain of Photobacterium phosphoreum; PL-721, a bright strain of Photobacterium leiognathi.

Media composition and growth conditions. All experiments were conducted in liquid culture in $250 \mathrm{ml}$ Erlenmeyer flasks with side-arms under continuous aeration in a temperature-controlled gyrotary shaker (New Brunswick, model G15) at $150 \mathrm{rev} \cdot \mathrm{min}^{-1}$. The bacteria were grown on either SWC medium $[1175 \%$ ( $\mathrm{v} / \mathrm{v}$ ) aged seawater, $5 \mathrm{~g}$ peptone, $3 \mathrm{~g}$ yeast extract, $3 \mathrm{ml}$ glycerol] or $\mathrm{SSW}$ medium [11 distilled water, $30 \mathrm{~g}$ $\mathrm{NaCl}, 7 \mathrm{~g} \mathrm{Na}_{2} \mathrm{HPO}_{4} .7 \mathrm{H}_{2} \mathrm{O}, 1 \mathrm{~g} \mathrm{KH}_{2} \mathrm{PO}_{4}, 0 \cdot 1 \mathrm{~g} \mathrm{MgSO}_{4}, 3 \mathrm{ml}$ glycerol]. The complex medium of Ulitzur \&

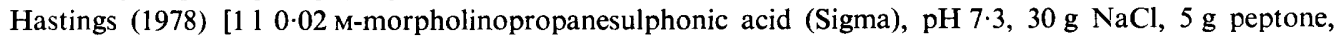
$3 \mathrm{~g}$ yeast extract, $0 \cdot 1 \mathrm{~g} \mathrm{MgSO}_{4}$ ] was also used for comparative studies. Neither SWC nor complex medium contained additional inorganic phosphate, so for selected experiments, inorganic phosphate (i.e. phosphate buffer, $\mathrm{pH}$ 7.3) was added as indicated.

Cell density and growth were measured with a Coleman Jr II spectrophotometer (absorbance at $660 \mathrm{~nm}$ ). For selected experiments, cell numbers were determined either by viable count on SWC agar, or by electronic particle counting (Coulter Electronics, model ZBI, $30 \mu \mathrm{m}$ aperture). Since individual cell size was found to vary considerably over the course of these experiments, most of the parameters are expressed per unit of absorbance or per $\mathrm{ml}$ of the culture medium. Using the methods of Niven et al. (1977) we calculated that $A_{660}$ is linearly related to dry weight between 0.1 and 1.0 ; an $A_{660}$ of 1.0 is equivalent to $0.4 \mathrm{mg}$ bacterial dry wt $\mathrm{ml}^{-1}$.

Autoinducer. In some experiments it was necessary to add autoinducer to cell preparations to stimulate the synthesis of luciferase: $10 \mu \mathrm{l}$ of a purified preparation of autoinducer $(N-\beta$-ketohexanoyl-homoserine lactone) containing approximately $2 \mathrm{mg} \mathrm{ml}^{-1}$ was added per $10 \mathrm{ml}$ culture.

Bioluminescence determinations. Luminescence in vivo was determined using a photomultiplier assembly as described by Nealson (1977). Light emission is expressed as light units (LU) per $\mathrm{ml}$ culture, where $1 \mathrm{LU}$ is equal to approximately $2 \times 10^{10}$ quanta s ${ }^{-1}$, as determined by the standard of Hastings \& Weber (1963). The preferred methods of standardization of light measurements are unfortunately still not well established. The absolute quanta reported here may differ by as much as a factor of two from absolute values (Hastings, 1975; Hastings \& Nealson, 1977; Wampler, 1978).

Oxygen uptake measurements. Oxygen uptake was determined using an oxygen electrode (Rank Bros, Cambridge). At predetermined intervals, a 2 to $3 \mathrm{ml}$ portion of the culture (or dilution thereof) was transferred from the flask to the temperature-controlled reaction chamber, and the rate of oxygen consumption was measured over a 20 to $30 \mathrm{~s}$ period. The respiration rate is expressed as $\mathrm{nmol} \mathrm{O}_{2}$ consumed $\left(A_{660} \mathrm{unit}^{-1} \mathrm{~min}^{-1}\right.$.

Nucleotide extraction and analysis. Cellular nucleotides were extracted by rapidly $(\leqslant 1 \mathrm{~s})$ injecting a small portion ( 50 to $100 \mu \mathrm{l}$ ) of the cell suspension directly into $5 \mathrm{ml}$ of boiling $0.02 \mathrm{M}$-Tris buffer $\mathrm{pH} \mathrm{7.75}$. The cells were extracted at $100{ }^{\circ} \mathrm{C}$ for $5 \mathrm{~min}$, and immediately frozen for subsequent analyses. An equivalent volume of cell-free extract $(0.22 \mu \mathrm{m}$ filtrate) was also extracted at each sampling period to monitor, and correct for, the occurrence of soluble nucleotides. AMP was the only nucleotide detected in the cell-free extracts, and a correction calculation was only necessary at extremely low cell densities $\left(<1 \times 10^{7}\right.$ cells $\left.\mathrm{ml}^{-1}\right)$. Yeast extract, rather than cell leakage, was found to be the source of the soluble AMP, and the concentration of dissolved AMP in the culture medium decreased during the course of each experiment.

ATP, ADP and AMP were determined using the firefly bioluminescent assay procedure described by Karl \& Holm-Hansen (1978). Peak height of light emission (0 to $3 \mathrm{~s}$ ) was measured using an ATP photometer (model 2000; SAI Technology, San Diego, Calif., U.S.A.) equipped with an automatic injector system (Kinetics kit, SAI Technology). The kinetics of the light emission reactions were monitored with a HewlettPackard (model 7155-B) strip chart recorder. Adenylate energy charge ratios were calculated from the molar concentrations of the individual adenine nucleotides, as described by Ball \& Atkinson (1975). GDP was added to the crude enzyme preparations, as suggested by Karl \& Holm-Hansen (1978), to reduce the interference resulting from the presence of non-adenine nucleotide triphosphates. For routine ATP analyses, GDP was added to the luciferase preparations to a final concentration of $400 \mathrm{ng} \mathrm{ml}^{-1}$ in the enzyme preparation. Since the firefly nucleoside diphosphokinase (NDPK) reaction is relatively non-specific, the addition of GDP will inhibit the reactivity of UTP, ITP and CTP to the same extent as GTP. GTP was measured using the nucleoside diphosphate kinase-firefly luciferase coupled reaction of Karl (1978a). All nucleotide concentrations are expressed as nmol $\left(A_{660} \text { unit }\right)^{-1}$ for each culture. 

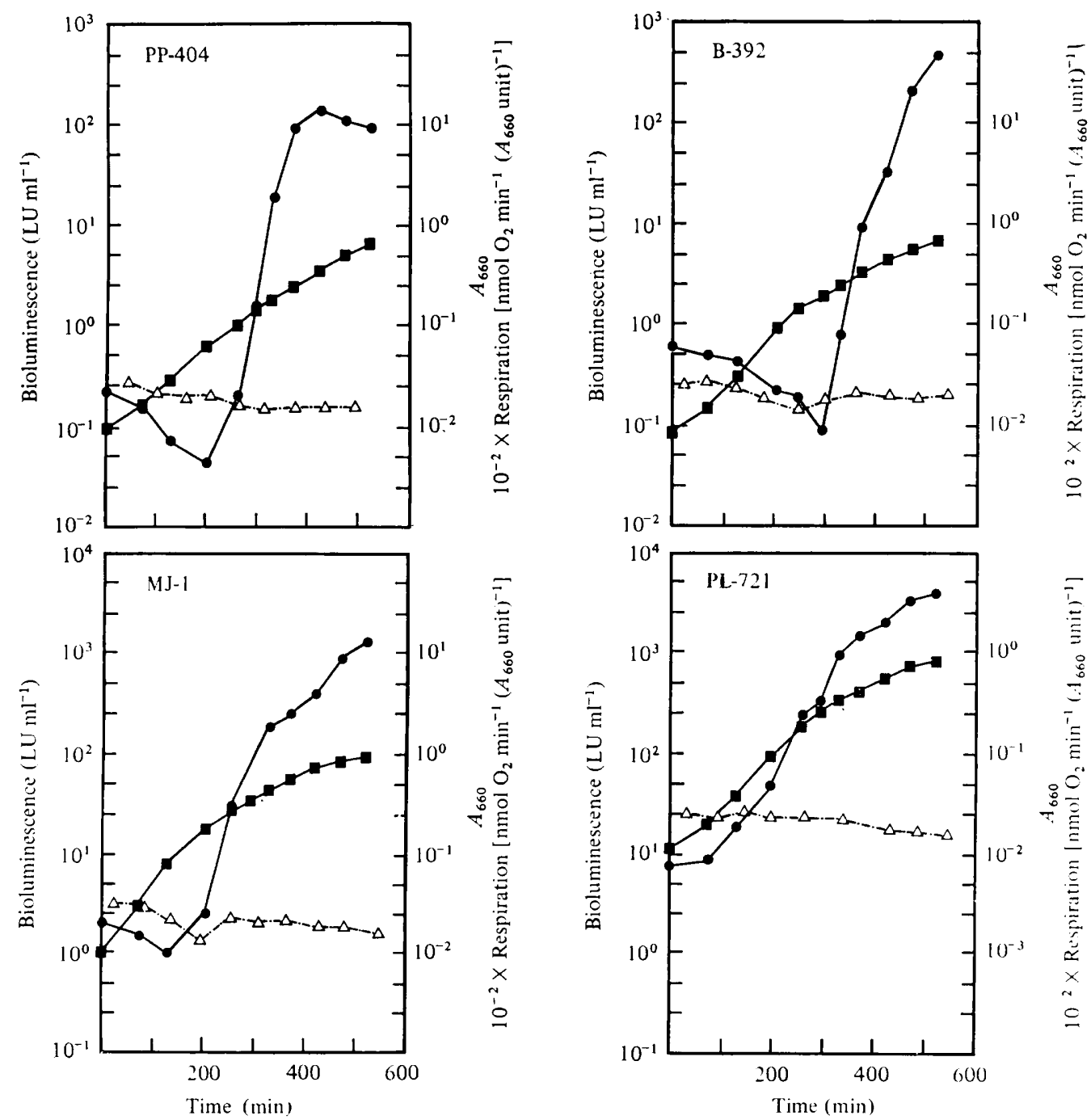

Fig. 1. Growth $(\boldsymbol{\square})$, bioluminescence $(\Theta)$ and respiration $(\triangle)$ for four species of luminous bacteria grown in SWC medium in batch culture. Specific growth conditions and medium composition are given in Methods.

\section{RESULTS AND DISCUSSION}

Growth, luminescence and respiration rate measurements for four different species of luminous bacteria are shown in Fig. 1. Early in growth luciferase synthesis lags and later proceeds at a rate greater than the rate of cell growth. This pattern, termed autoinduction, is the result of a control system mediated by the bacteria (Nealson et al., 1970; Nealson, 1977). For each bacterial strain there is an increase of approximately $10^{3}$ between the light emission of the pre-induced cells and the maximum levels measured. If the in vivo bioluminescence quantum yield is $10 \%$ (i.e. $0 \cdot 1$ quanta emitted per $\mathrm{O}_{2}$ molecule consumed) as indicated for the in vitro system (Hastings, 1975), then the proportion of the total $\mathrm{O}_{2}$ consumption due to the luciferase reaction can be determined for any given level of luciferase activity. At pre-induced levels of light emission, between 0.04 and $29 \%$ of the total $\mathrm{O}_{2}$ consumption can be attributed to the luminescent reaction (Table 1). At maximum luciferase activity, however, the calculated $\mathrm{O}_{2}$ utilization of the light emission reaction reaches, in some cases, $100 \%$ or more of the total measured $\mathrm{O}_{2}$ consumption rates (with the 
Table 1. Calculated oxygen consumption rates for the bioluminescent systems of four species of luminous bacteria at minimum and maximum levels of luciferase activity

\begin{tabular}{|c|c|c|c|}
\hline \multirow[b]{2}{*}{ Culture* } & \multirow{2}{*}{$\begin{array}{c}\text { Total } \mathrm{O}_{2} \\
\text { utilization } \\
(\mathrm{nmol} \\
\left.\mathrm{ml}^{-1} \mathrm{~min}^{-1}\right)\end{array}$} & \multicolumn{2}{|c|}{ Bioluminescence activity } \\
\hline & & $\left(\mathrm{LU}+\mathrm{ml}^{-1}\right)$ & $\begin{array}{c}\text { (quanta } \\
\mathrm{ml}^{-1} \min ^{-1} \text { ) }\end{array}$ \\
\hline $\begin{array}{ll}\text { MJ-1 } & (a) \\
& (b)\end{array}$ & $\begin{array}{r}0 \cdot 7 \\
14 \cdot 7\end{array}$ & $\begin{array}{c}1 \\
1300\end{array}$ & $\begin{array}{r}1.2 \times 10^{12} \\
1.56 \times 10^{15}\end{array}$ \\
\hline $\begin{array}{r}\text { PL-721 (a) } \\
(b)\end{array}$ & $\begin{array}{r}0.5 \\
15 \cdot 0\end{array}$ & $\begin{array}{r}7 \\
4000\end{array}$ & $\begin{array}{l}8.4 \times 10^{12} \\
4.8 \times 10^{15}\end{array}$ \\
\hline $\begin{array}{r}\text { PP-404 (a) } \\
(b)\end{array}$ & $\begin{array}{r}2 \cdot 1 \\
14 \cdot 0\end{array}$ & $\begin{array}{c}4.5 \times 10^{-2} \\
140\end{array}$ & $\begin{array}{r}5.4 \times 10^{10} \\
1.68 \times 10^{14}\end{array}$ \\
\hline $\begin{array}{ll}\text { B-392 } & (a) \\
& (b)\end{array}$ & $\begin{array}{r}2 \cdot 0 \\
10 \cdot 0\end{array}$ & $\begin{array}{c}9 \times 10^{-2} \\
500\end{array}$ & $\begin{array}{r}1.1 \times 10^{11} \\
6 \times 10^{14}\end{array}$ \\
\hline
\end{tabular}

\begin{tabular}{|c|c|}
\hline \multicolumn{2}{|c|}{$\begin{array}{l}\text { Luciferase } \mathrm{O}_{2} \text { utilization } \ddagger \\
\quad\left(\mathrm{nmol} \mathrm{m} \mathrm{m}^{-1} \mathrm{~min}^{-1}\right)\end{array}$} \\
\hline \multicolumn{2}{|c|}{ Quantum efficiency } \\
\hline $10 \%$ & $100 \%$ \\
\hline $\begin{array}{r}2 \times 10^{-2}(3) \\
26(177)\end{array}$ & $\begin{array}{r}2 \times 10^{-3}(0 \cdot 3) \\
2 \cdot 6(17 \cdot 7)\end{array}$ \\
\hline $\begin{array}{c}0 \cdot 14(29) \\
80(533)\end{array}$ & $\begin{array}{r}1.4 \times 10^{-2}(2.9) \\
8(53)\end{array}$ \\
\hline $\begin{array}{c}9 \times 10^{-4}(0.04) \\
2.8(20)\end{array}$ & $\begin{array}{c}9 \times 10^{-5}(<0.01) \\
0.28(2)\end{array}$ \\
\hline $\begin{array}{r}1.8 \times 10^{-3}(0.09) \\
10(100)\end{array}$ & $\begin{array}{c}1.8 \times 10^{-4}(<0.01) \\
1(10)\end{array}$ \\
\hline
\end{tabular}

* (a) Pre-induced levels of bioluminescence; $(b)$ maximum levels of bioluminescence.

$\dagger 1 \mathrm{LU}=2 \times 10^{10}$ quanta $\mathrm{s}^{-1}$.

$\ddagger$ Values in parentheses indicate the percentage of the total $\mathrm{O}_{2}$ utilization that is consumed via luciferase activity.

exception of PP-404, Table 1). These results suggest that the quantum efficiency in vivo must be greater than $10 \%$. For instance, if the quantum efficiency for $\mathrm{O}_{2}$ were $100 \%$, then the maximum luciferase $\mathrm{O}_{2}$ consumption rates would range from 2 to $53 \%$ of the measured rates of $\mathrm{O}_{2}$ consumption. These results are not only acceptable in terms of cellular metabolism but are also consistent with the reports of other workers. Furthermore, the results strongly suggest that the bioluminescence quantum yield in vivo is much greater than previously measured in vitro. It should be noted that the development and expression of the luminous system affect neither the growth rate $\left(\Delta A_{660} \mathrm{~min}^{-1}\right)$ nor the respiration rate $\left[\Delta \mathrm{O}_{2}\left(A_{660} \text { unit }\right)^{-1}\right]$, suggesting that the cells are well regulated with regard to the distribution of cellular energy. Another possible source of error in these calculations involves the determination of the absolute number of quanta (see Methods), which could be overestimated by as much as a factor of two. However, even if a twofold correction factor is applied, the quantum efficiency in vivo must still be greater than $10 \%$ to make the results given in Table 1 acceptable.

Experiments were conducted to determine whether induction and expression of the luminescent system had an effect on the intracellular ATP pools. Luminescence and ATP pools were monitored during growth in batch cultures for both a bright strain (MJ-1) and a luminescence-conditional strain (B-61) of $P$. fischeri. Strain B-61 is very dim unless autoinducer is added to the medium (Fig. $2 a$ ); in fact, B-61 can be used in a bioassay for autoinducer (Nealson, 1977). The luminescence of strain MJ-1 was only slightly enhanced by addition of autoinducer (Fig. $2 b$ ). In all cases induction of luminescence occurred, although to widely different extents (MJ-1 + inducer $>\mathrm{MJ}-1>\mathrm{B}-61+$ inducer $\gg \mathrm{B}-61)$, and in no case were changes in either the ATP pools or the growth rates noted (Fig. 2).

The photons emitted during bacterial bioluminescence are equivalent to about $50 \mathrm{kcal}$ $(200 \mathrm{~kJ})$ per Einstein (Hastings \& Nealson, 1977), which represents an energy investment corresponding to at least 6 to 7 molecules of ATP per photon (assuming 100\% efficiency). Even though ATP is not directly consumed in the light emission reaction, the oxidation of the reduced flavin and of the aldehyde molecule may represent a potential competition for electrons for ATP synthesis.

Since the luciferase in fully induced cells may be as much as $5 \%$ of the soluble cellular protein, the biosynthetic energy requirements should also be considered. Assuming that the soluble protein pool is $90 \%$ of the total cellular protein (Mandelstam \& McQuillen, 

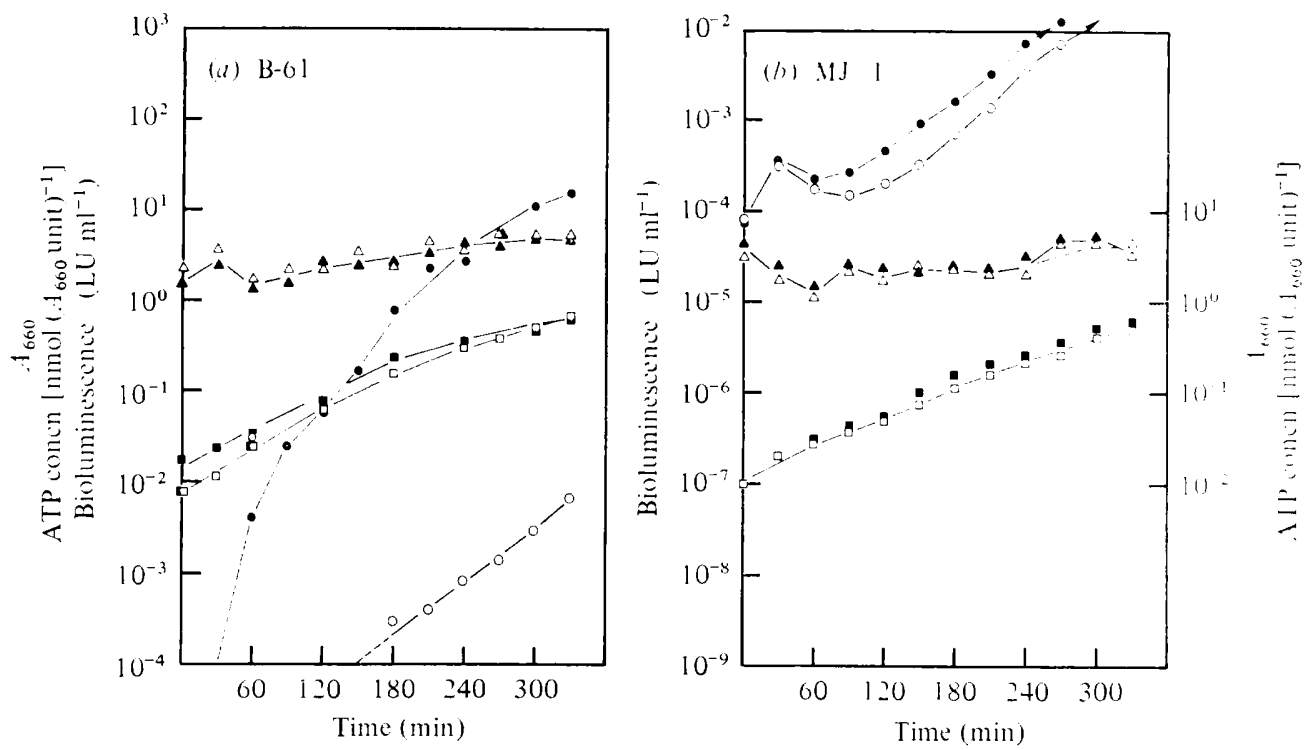

Fig. 2. Growth $(\square, \square)$, bioluminescence $(\boldsymbol{O}, \bigcirc)$ and cellular ATP concentrations $(\boldsymbol{\Delta}, \ldots)$ of a bright strain of Photobacterium fischeri (MJ-1) and an inducer-negative strain (B-61) of the same species grown in SWC medium in batch culture with $(\mathbf{O}, \mathbf{D}, \mathbf{\Delta})$ and without $(\mathrm{O},[,, \Delta)$ the addition of exogenous inducer.

Table 2. Calculated minimum ATP requirements for bioluminescence at maximum luciferase induction for a naturally occurring inducer-negative mutant, B-61 (with and without exogenous inducer) and the bright wild-type strain $\mathrm{MJ}-1$

\begin{tabular}{|c|c|c|c|c|c|}
\hline \multirow[b]{3}{*}{ Strain* } & \multicolumn{2}{|c|}{ Bioluminescence } & \multirow{3}{*}{$\begin{array}{c}\text { ATP pool } \\
{[\text { mol }} \\
\left.\left(A_{660} \text { unit }\right)^{-1}\right]\end{array}$} & \multirow{2}{*}{\multicolumn{2}{|c|}{$\begin{array}{c}\begin{array}{c}\text { for bioluminescence } \\
{\left[\text { mol }\left(A_{660} \text { unit }^{-1}\right]\right.}\end{array} \\
\text { Quantum efficiency }\end{array}$}} \\
\hline & \multirow{2}{*}{$\begin{array}{c}{[\mathrm{LU}} \\
\left(A_{660} \text { unit }^{-1}\right]\end{array}$} & \multirow{2}{*}{$\begin{array}{l}\text { [quanta s }{ }^{-1} \\
\left.\left(A_{660} \text { unit }\right)^{-1}\right]\end{array}$} & & & \\
\hline & & & & $10 \%$ & $100 \%$ \\
\hline $\mathrm{B} 61(-)$ & $1 \times 10^{-9}$ & $2 \times 10^{1}$ & $5.46 \times 10^{-9}$ & $2 \times 10^{-21}$ & $2 \times 10^{-22}$ \\
\hline B61 (+) & $2 \cdot 5 \times 10^{-4}$ & $5 \times 10^{6}$ & $5 \cdot 13 \times 10^{-9}$ & $5 \times 10^{-16}$ & $5 \times 10^{-17}$ \\
\hline MJ-1 & $2 \cdot 7 \times 10^{2}$ & $5.4 \times 10^{12}$ & $5.52 \times 10^{-9}$ & $5 \cdot 4 \times 10^{-10}$ & $5.4 \times 10^{11}$ \\
\hline
\end{tabular}

1973), and that it requires $2 \cdot 1 \times 10^{6}$ molecules ATP $\mathrm{s}^{-1}$ cell ${ }^{-1}$ to synthesize the protein required for the biosynthesis of a 'typical' bacterial cell (Lehninger, 1971), then the synthesis of luciferase might be expected to require $0.95 \times 10^{5}$ molecules ATP s ${ }^{-1}$ cell $^{-1}$. These, of course, are effective ATP values, since the primary consumption of nucleotide triphosphates will be that of GTP.

Taken together, the synthesis and activity of the luminous system appear to represent a large energy commitment or drain, yet none of the parameters measured (growth rate, respiration rate or intracellular ATP pools) were affected by either the synthesis or activity of the bioluminescent system. That is, the metabolism of light emission, for all species studied, is well integrated and controlled in relation to other cellular functions. Furthermore, the ATP pool simply represents the steady-state intracellular concentration of ATP and cannot be regarded as a reserve of metabolic energy. Harrison \& Maitra (1969) have reported that changes in respiration rate did not result in changes in the ATP pools of Klebsiella aerogenes, but rather affected the half-life or turnover time of the ATP pool.

The results in Fig. 2 are presented in Table 2 for the purpose of examining the magnitude 


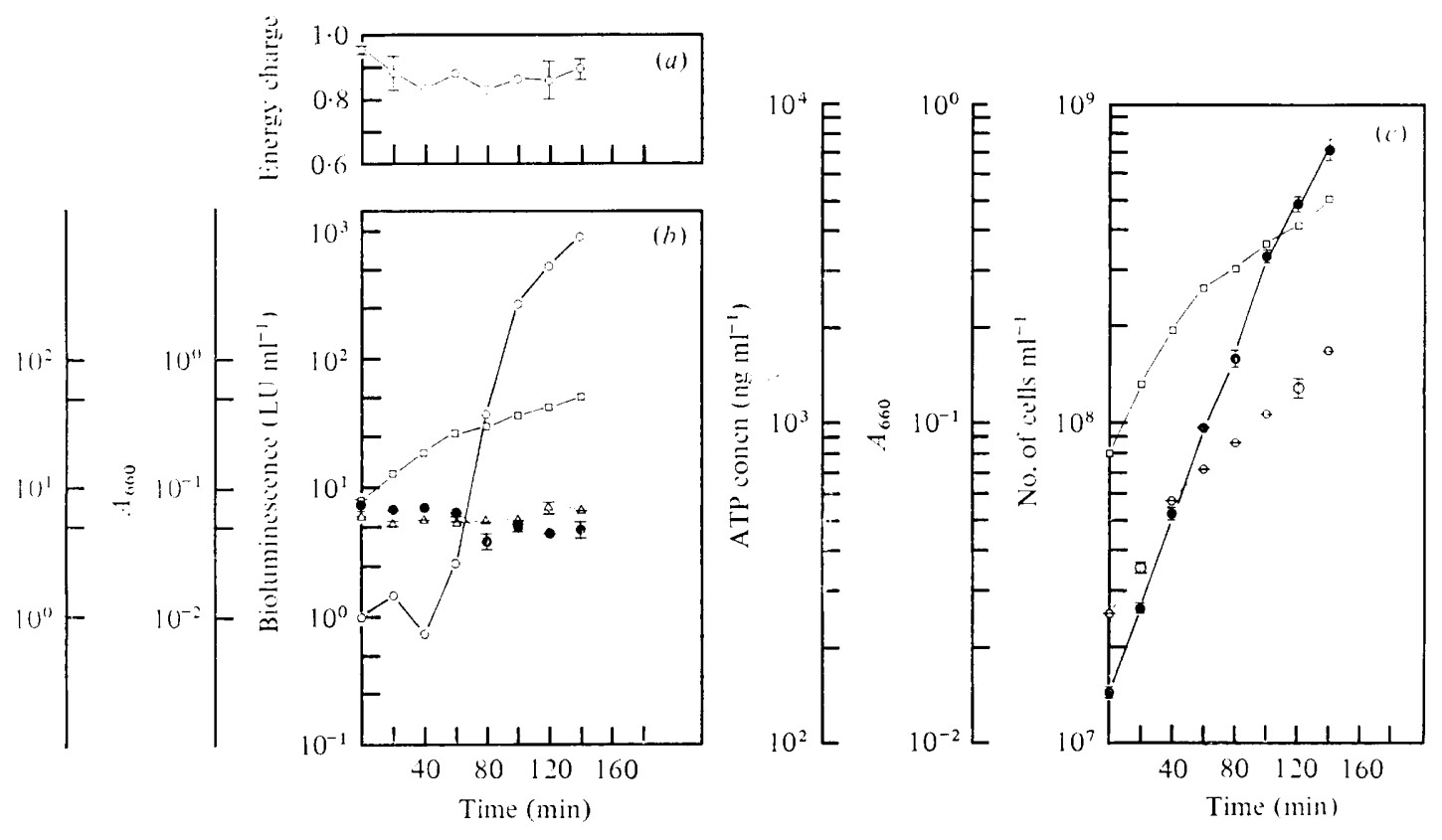

Fig. 3. Beneckea harveyi (B-392) was grown in SSW medium in batch culture and the following properties were measured: $(a)$ energy charge; $(b)$ growth $(\square)$, bioluminescence $(\bigcirc)$ and cellular ATP $(\triangle)$ and GTP $(O)$ concentrations; $(c)$ growth $(\square)$, cell numbers $(\odot)$ and cellular ATP concentrations $(\bigcirc)$. Specific growth conditions and medium composition are given in Methods.

of the energy commitment to bioluminescence. Here the minimum cellular ATP requirements for bioluminescence are calculated for each strain. If the quantum efficiency is assumed to be 0.1 with respect to all substrates, then at maximum luminescence, light emission can conceivably decrease ATP production (by shunting electrons to luciferase) by as much as $10 \%$. As discussed above, the quantum efficiency seems to be much higher, making the energy drain less than $10 \%$, even at maximum luminescence. These calculations do not include the possibly significant biosynthetic requirement for luciferase and associated proteins that are co-induced with luciferase. By comparison, light emission is never a significant energy factor for the uninduced dark mutant, suggesting that unless the luminescence itself confers some selective advantage to the bacteria, the dark mutants should always have a selective advantage, based solely on an energy argument.

Ulitzur \& Hastings (1978) reported that the intracellular ATP pool in B. harveyi (MAV, B-392) decreased significantly (10- to 20-fold) during or immediately prior to the period of luciferase induction. One hypothesis they considered was that the decrease in ATP resulted from an uncoupling of oxidative phosphorylation, the result of the overproduction of a specific fatty acid precursor during aldehyde synthesis. In the experiments shown above, we observed no such decrease in ATP pools, but some methodological differences were apparent, so we conducted experiments using the same organism (B-392) and growth medium as Ulitzur \& Hastings (1978). These experiments also indicated that the intracellular ATP pool decreased at or near the time of luciferase induction (results not shown); however, the decrease did not appear to be obligatorily associated with induction. Furthermore, the apparent decrease was always accompanied by a dramatic fall in the cellular adenylate energy charge to values well below those considered to be minimal for the maintenance of cell viability (i.e. energy charge less than $0 \cdot 4$; Knowles, 1977). These effects occurred without any apparent decrease in the growth rate, and therefore appeared to be inconsistent with the currently accepted theories of regulation of cell growth and meta- 
bolism by the adenylate energy charge (Atkinson, 1969; Chapman \& Atkinson, 1977; Knowles, 1977). When this experiment was repeated using SSW medium (Fig. 3), essentially all parameters measured remained constant, and the adenylate energy charge remained consistently high $(0.82$ to 0.95$)$ throughout the experiment (Fig. $3 a$ ).

At this point it is appropriate to discuss three methodological considerations that not only partially explain the disparities between our results and those of Ulitzur \& Hastings (1978), but are important in all experimental work of this kind. The first involves changes in cell volume during growth. The preferred method for expressing cellular nucleotide levels involves normalization to cellular dry weight (or protein) rather than to cell number. Using an electronic particle counter (Coulter Electronics, model ZBI), we have monitored discrete changes in cell size and size distribution at all stages of growth and have observed considerable differences (from 3- to 10-fold) in the mean intracellular volume of the cells at various stages of growth. As a result, we have presented all of our data in terms of ATP per absorbance unit, a more reliable and consistent assessment of the intracellular environment. Absorbance units can be converted to $\mathrm{mg}$ dry wt or $\mathrm{mg}$ protein as described in Methods. The total ATP concentration in the culture medium more closely parallels the absorbance measurements than the absolute number of cells in the medium (Fig. $3 c$ ). If the ATP concentrations presented in Fig. 3 were expressed in terms of ATP cell ${ }^{-1}$, rather than on the basis of absorbance, we would have calculated a decrease in the ATP cell ${ }^{-1}$ simply because $^{-1}$ the cell volume decreased 2- to 4-fold with time.

The second consideration pertains to the actual methods used to determine the concentrations of ATP by the firefly luciferase reaction. Even though crystalline firefly luciferase is specific for ATP (McElroy \& Green, 1956; DeLuca, 1976), commercially available reagents are much less specific for their nucleotide triphosphate substrate, primarily due to contaminating transphosphorylase enzyme activities. As a result, total light emission will depend on the sum of all of the intracellular nucleotide triphosphates (NTPs). During periods of rapid cell growth and biosynthesis the intracellular concentrations of nonadenine NTPs increase relative to the levels of ATP. This source of analytical interference in the ATP assay has been discussed in detail by Rasmussen \& Nielsen (1968), Rhee et al. (1975) and Lundin \& Thore (1975). Since the kinetics of the ATP-dependent light emission reaction differ from the kinetics of GTP, UTP, ITP and CTP reactivity, the extent of analytical interference will depend on the actual methods used to measure the light emission. The two techniques most commonly employed depend on the measurement of either the peak height of light emission or an integration of the light flux over some predetermined portion of the subsequent decay curve. Our results indicate that even measurements of peak heights yield overestimates of the true ATP levels due to the high concentrations of nonadenine NTPs at the growth rates observed in our experiments. Therefore, we found it necessary to alter our crude firefly luciferase preparations chemically to increase their reaction specificity as follows.

Figure 4(a) shows the effect of the addition of GDP to the crude luciferase preparations on the reactivity of standard ATP and GTP solutions. GTP was selected as a representative NTP since it is the fastest reacting and therefore would result in the greatest degree of interference (on a molar basis). As increasing amounts of exogenous GDP were added to the crude luciferase preparations, the kinetics and extent of GTP reactivity were greatly reduced, without changing the ATP-dependent light emission reaction. Figure $4(b, c)$ show representative light emission curves for a bacterial cell extract without and with exogenous GDP to emphasize the importance of this procedure for obtaining accurate ATP measurements.

During the early exponential phase of growth in batch cultures, the intracellular GTP concentrations (on a molar basis) are actually greater than the corresponding cellular ATP pools (Fig. $3 b$ ). These high GTP/ATP ratios (i.e. $>1$ ) have been confirmed in chemostat experiments with luminous as well as non-luminous bacteria (D. M. Karl, unpublished 

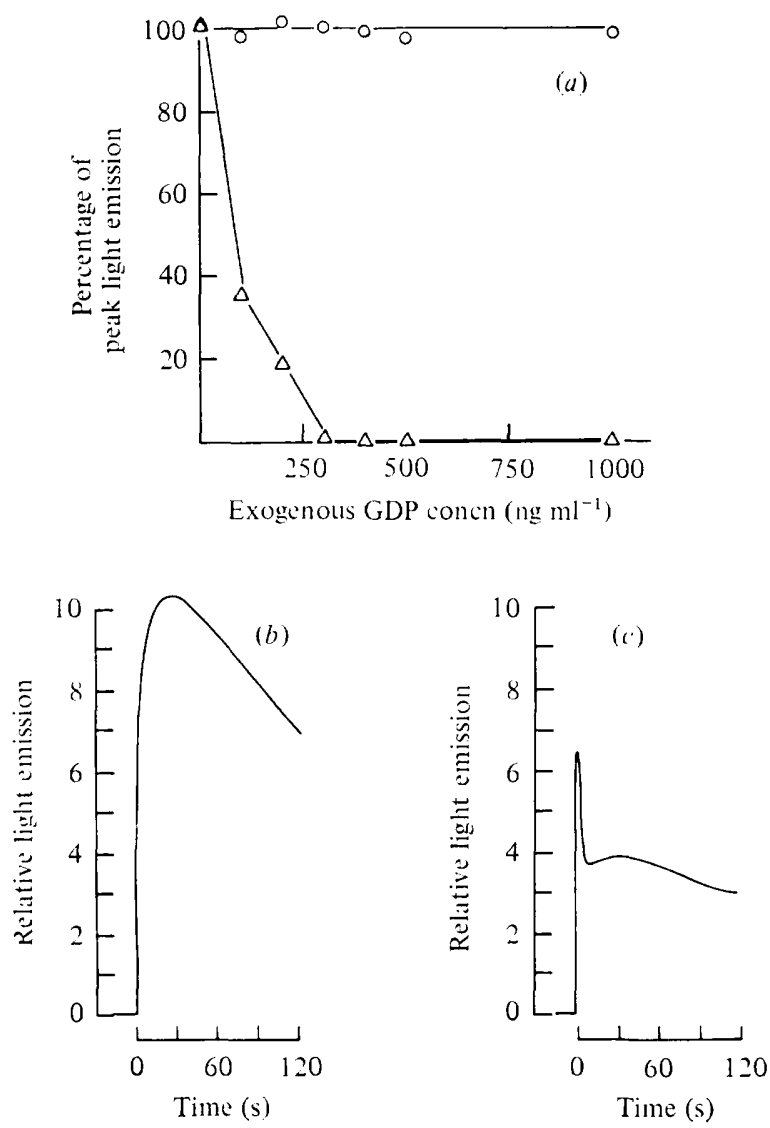

Fig. 4. Effects of GDP addition on the ATP- and GTP-dependent bioluminescence reactions using crude firefly luciferase (FLE-50). (a) Initial ATP $(O)$ and GTP $(\triangle)$ concentrations were $2 \times 10^{-8} \mathrm{M}$. $(b, c)$ Bioluminescent reaction kinetics catalysed by the injection of a representative bacterial sample extract into crude firefly luciferase in the absence $(b)$ or presence $(c)$ of GDP $\left(400 \mathrm{ng} \mathrm{ml}^{-1}\right)$.

results). The GTP/ATP ratio in micro-organisms appears to be directly related to the rate of cell growth (Karl, 1978b).

The final methodological consideration is the occurrence of a heat-stable ATPase activity within the luminous bacteria under certain culture conditions. If $B$. harveyi (B-392) is grown on SWC medium or the complex medium of Ulitzur \& Hastings (1978), an ATPase (alkaline phosphatase?) activity is induced, presumably in response to inorganic phosphate limitation. The presence and relative amount of this activity can be determined by measuring the temporal stability of an added ATP internal standard in the presence of a portion of the bacterial cell extracts. If the enzyme activity is absent, the internal ATP standard will be stable with time. However, in the presence of the ATPase activity there will be a timedependent, temperature-dependent hydrolysis of the exogenous ATP. The rate at which the ATP disappears can be used as a relative measure of the enzyme activity. We found an inverse relationship between the inorganic phosphate concentration of the growth medium and the ATPase activity in the final cell extracts (Fig. 5). (Details of the experiment are given in the legend to Fig. 5.) That the ATPase activity appears under conditions of inorganic phosphate limitation suggests that this activity represents a general alkaline phosphatase activity such as the one described by Torriani (1960) and Garen \& Levinthal (1960) for Escherichia coli, which is induced under similar culture conditions (i.e. low phosphate). Subsequent investigations with $B$. harveyi revealed that greater than $95 \%$ of 


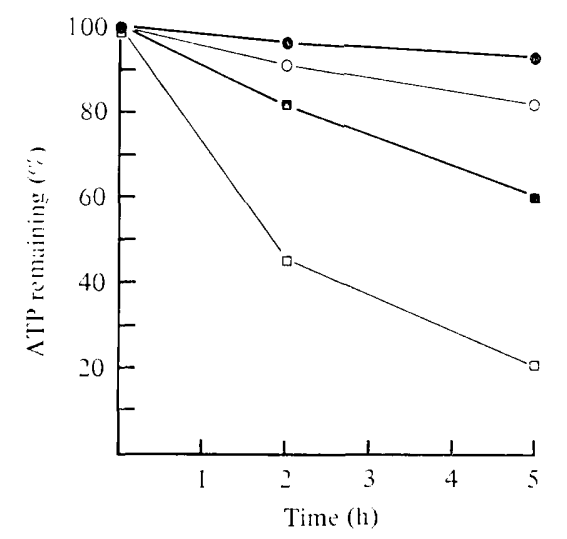

Fig. 5. Stability of exogenous ATP in cell extracts of Beneckea harveyi (B-392). Cells were grown in SWC medium containing $0(\square), 30 \mu \mathrm{M}(\mathbf{\square}), 100 \mu \mathrm{M}(\bigcirc)$ and $300 \mu \mathrm{M}(O)$ inorganic phosphate. When the cultures reached an $A_{660}$ of 0.5 they were extracted as described in Methods. After the extracts had cooled, exogenous ATP $\left(100 \mathrm{ng} \mathrm{ml}^{-1}\right)$ was added to each extract and the stability at $25{ }^{\circ} \mathrm{C}$ was monitored by measuring the percentage of the ATP remaining using the firefly bioluminescent reaction.

the ATPase activity is contained within the cells (i.e. is filterable). This activity might be similar to the acid-stable alkaline phosphatase activity reported by Davison \& Fynn (1974) for Bacillus subtilis. In any case, it is imperative to monitor the fate of ATP internal standards in the various cell extracts to determine whether or not this ATPase activity is present. Since Ulitzur \& Hastings (1978) employed similar culture conditions to those described for the experiment reported in Fig. 5, the observed dip in the cellular ATP pools may be related to inorganic phosphate exhaustion and the induction of the phosphatase activity, rather than to luciferase induction per se. In fact, when $B$. harveyi was grown in minimal medium (high phosphate) no dip in the ATP pool was observed (see Fig. 9 in Ulitzur \& Hastings, 1978), even after the addition of arginine, a specific stimulator of the synthesis of the luminescent system (Coffey, 1967; Nealson et al., 1970).

Our data on luminescence, growth, respiration rates and ATP pools suggest that the synthesis and expression of luciferase in luminous bacteria does not represent a large bioenergetic drain on cellular metabolism. The observed constancy of the ATP levels and energy charge ratios (Fig. $3 a, b$ ) conform to the general notions presented by Atkinson and others (Atkinson, 1969; Chapman \& Atkinson, 1977; Knowles, 1977) for metabolic regulation by the adenine nucleotides. The calculations presented in Table 1 based on mass balance $\mathrm{O}_{2}$ utilization rates indicate that the light emission quantum yield in vivo must be greater than the $10 \%$ previously measured for the system in vitro. Even if the efficiency is $100 \%$, however, certain bright strains such as PL-721 (Table 1) appear to consume the majority of their total $\mathrm{O}_{2}$ utilization via luciferase, with no apparent effect on the normal functioning and growth of the cells. These results are consistent with the model proposed by Watanabe et al. (1975) for P. phosphoreum. In this model, they proposed that during the early stages of growth the coupling of NADH oxidation to the cytochromes prevails over luciferase, but at later stages of growth some unknown change occurs in the mode of competition and a greater percentage of the electrons flow through luciferase.

Irrespective of the control mechanisms involved, the energetic commitment to bioluminescence is apparently quite small. There was no detectable effect on the growth rates in batch cultures when dark and bright cells of the same strain were compared (Fig. 2). Nevertheless, it seems likely, based on the results presented in this report, that the luminescent system constitutes a detectable energy commitment. Such subtle effects might be more appropriately investigated via competition studies (between bright and dark strains) in chemostat cultures. Such studies are now underway in our laboratory. 


\section{REFERENCES}

Atkinson, D. E. (1969). Regulation of enzyme function. Annual Review of Microbiology 23, 47-68.

Ball, W. J. \& Atkinson, D. E. (1975). Adenylate energy charge in Saccharomyces cerevisiae during starvation. Journal of Bacteriology 121, 975-982.

Chapman, A. G. \& Atkinson, D. E. (1977). Adenine nucleotide concentration and turnover rates. Their correlation with biological activity in bacteria and yeasts. Advances in Microbial Physiology 15, 253-306.

Coffey, J. J. (1967). Inducible synthesis of bacterial luciferase: specificity and kinetics of induction. Journal of Bacteriology 94, 1638-1647.

DAvison, J. A. \& FYNN, G. H. (1974). The assay of ATP by the luciferin-luciferase method. Interference by a bacterial phosphatase enzyme stable to perchlorate treatment. Analytical Biochemistry 58, 632-637.

DeLuCA, M. (1976). Firefly luciferase. Advances in Enzymology 44, 37-68.

Garen, A. \& Levinthal, C. (1960). A fine-structure genetic and chemical study of the enzyme alkaline phosphatase of $E$. coli. I. Purification and characterization of alkaline phosphatase. Biochimica et biophysica acta 38, 470-483.

Harrison, D. E. F. \& Maitra, P. K. (1969). Control of respiration and metabolism in growing Klebsiella aerogenes. The role of adenine nucleotides. Biochemical Journal 112, 647-656.

HARveY, E. N. (1952). Bioluminescence. New York: Academic Press.

Hastings, J. W. (1975). Bioluminescence: from chemical bonds to photons. In Energy Transformation in Biological Systems, Ciba Foundation Symposium 31, pp. 125-146. Edited by G. E. W. Wolstenholme \& D. W. Fitzsimons. Amsterdam: Associated Scientific Publishers.

Hastings, J. W. \& Nealson, K. H. (1977). Bacterial bioluminescence. Annual Review of Microbiology 31, 549-595.

Hastings, J. W. \& Weber, G. (1963). Total quantum flux of isotopic sources. Journal of the Optical Society of America 53, 1410-1415.

Hastings, J. W., Riley, W. H. \& Massa, J. (1965). The purification, properties and chemiluminescent quantum yield of bacterial luciferase. Journal of Biological Chemistry 240, 1473-1481.

Henry, J. P. \& Michelson, A. M. (1970). Etudes de bioluminescence. Regulation de la bioluminescence bactérienne. Compte rendu hebdomadaire des séances de l'Académie des sciences 270, 1947-1949.

KARL, D. M. (1978a). A rapid sensitive method for the measurement of guanine ribonucleotides in bacterial and environmental extracts. Analytical Biochemistry 89, 581-595.

KARL, D. M. (1978b). Occurrence and ecological significance of GTP in the ocean and in microbial cells. Applied and Environmental Microbiology 36, 349-355.

Karl, D. M. \& Holm-Hansen, O. (1978). Methodology and measurement of adenylate energy charge ratios in environmental samples. Marine Biology 48, 185-197.
KNowles, C. J. (1977). Microbial metabolic regulation by adenine nucleotide pools. Symposia of the Society for General Microbiology 27, 241283.

Lehninger, A. L. (1971). Bioenergetics, chapter 7. Menlo Park, California: W. A. Benjamin.

Lundin, A. \& Thore, A. (1975). Analytical information obtainable by evaluation of the time course of frefly bioluminescence in the assay of ATP. Analytical Biochemistry 66, 47-63.

Mandelstam, J. \& McQuillen, K. (1973). Biochemistry of Bacterial Growth, 2nd edn. New York: John Wiley.

McElroy, W. D. \& Green, A. (1956). Function of adenosine triphosphate in the activation of luciferin. Archives of Biochemistry and Biophysics 64, 257-271.

Michaliszyn, G. A. \& Meighen, E. A. (1976). Induced polypeptide synthesis during the development of bacterial bioluminescence. Journal of Biological Chemistry 251, 2541-2549.

Miovic, M. L. \& Gibson, J. (1973). Nucleotide pools and adenylate energy charge in balanced and unbalanced growth of Chromatium. Journal of Bacteriology 114, 86-95.

Nealson, K. H. (1977). Autoinduction of bacterial luciferase. Occurrence, mechanism and significance. Archives of Microbiology 112, 73-79.

Nealson, K. H. \& Hastings, J. W. (1977). Low oxygen is optimal for luciferase synthesis in some bacteria. Ecological implications. Archives of Microbiology 112, 9-16.

Nealson, K. H., Platt, T. \& Hastings, J. W. (1970). Cellular control of the synthesis and activity of the bacterial luminescent system. Journal of Bacteriology 104, 313-322.

Ne'eman, Z., Ulitzur, S., Branton, D. \& Hastings, J. W. (1977). Membrane polypeptides co-induced with the bacterial bioluminescent system. Journal of Biological Chemistry 252, 5150-5154.

Niven, D. F., Collins, P. A. \& Knowles, C. F. (1977). Adenylate energy charge during batch culture of Beneckea natriegens. Journal of General Microbiology 98, 95-108.

Rasmussen, H. \& Nielsen, R. (1968). An improved analysis of adenosine triphosphate by the luciferase method. Acta chemica scandinavica $\mathbf{2 2}$, 1745-1756.

Reichelt, J. L. \& BaumanN, P. (1973). Taxonomy of the marine, luminous bacteria. Archiv für Mikrobiologie 94, 283-330.

Rhee, S. G., Greifner, M. I. \& Chock, P. B. (1975). Determination of adenosine- 5 '-triphosphate by the luciferin-luciferase system with a stopped-flow spectrometer. Analytical Biochemistry 66, 259264.

TORRIANI, A. (1960). Influence of inorganic phosphate in the formation of phosphatases by Escherichia coli. Biochimica et biophysica acta 38, 460-469.

Ulitzur, S. \& Hastings, J. W. (1978). Growth, luminescence, respiration, and the ATP pool during autoinduction in Beneckea harveyi. Journal of Bacteriology 133, 1307-1313. 
WAMPLER, J. E. (1978). Measurements and physical characteristics of luminescence. In Bioluminescence in Action, pp. 1-48. Edited by P. J. Herring. New York: Academic Press.
Watanabe, H., Mimura, N., Takimoto, A. \& Nakamura, T. (1975). Luminescence and respiratory activities of Photobacterium phosphoreum. Competition for cellular reducing power. Journal of Biochemistry 77, 1147-1155. 